\title{
MDRD 4 Variable Formula
}

National Cancer Institute

\section{Source}

National Cancer Institute. MDRD 4 Variable Formula. NCI Thesaurus. Code C161343.

A formula to estimate glomerular filtration rate that takes into account age, sex, race, and serum creatinine $(\mathrm{Scr})$. eGFR $(\mathrm{mL} / \mathrm{min} / 1.73 \mathrm{~m} 2)=186 \times(\mathrm{Scr})^{\wedge}-1.154 \times(\mathrm{Age})^{\wedge}-0.203 \times$ (0.742 if female) $\times$ (1.210 if African American). (Levey AS, Bosch JP, Lewis JB, Greene T, Rogers N, Roth D. A more accurate method to estimate glomerular filtration rate from serum creatinine: a new prediction equation. Modification of Diet in Renal Disease Study Group. Ann Intern Med. 1999;130:461-70.) 